\title{
Right putamen hemorrhage manifesting as apraxia of eyelid opening
}

\author{
This article was published in the following Dove Press journal: \\ Neuropsychiatric Disease and Treatment \\ 25 September 2013 \\ Number of times this article has been viewed
}

\author{
Yi-Hui Lin' \\ Li-Min Liou ${ }^{2,3}$ \\ Chiou-Lian Lai ${ }^{1,2}$ \\ Yang-Pei Chang',2 \\ 'Department of Neurology, Kaohsiung \\ Medical University Hospital, \\ ${ }^{2}$ Department of Neurology, Faculty \\ of Medicine, College of Medicine, \\ Kaohsiung Medical University, \\ ${ }^{3}$ Department of Neurology, Kaohsiung \\ Municipal Hsiao-Kang Hospital, \\ Kaohsiung Medical University, \\ Kaohsiung, Taiwan
}

Purpose: The purpose of this report is to demonstrate a rare clinical manifestation of apraxia eyelid opening related to a basal ganglia lesion.

Case report: In this study, we report a 91-year-old woman suffering from difficulty in eyelid opening after being treated for myocardial ischemia with dual antiplatelet medications. She could open her eyelid with fingers touching her forehead. Brain computed tomography revealed a right putamen hemorrhage. Surface electromyography revealed persistent frontalis muscle contraction during relaxation of orbicularis oculi muscles. Apraxia of eyelid opening was diagnosed. Her eyelid symptom resolved 2 months later.

Conclusion: Apraxia of eyelid opening may be caused by subcortical hemorrhage of the basal ganglia. In addition to the primary motor cortex and supplemental motor area, the basal ganglia may also play a role in eyelid opening.

Keywords: intracranial hemorrhage, basal ganglia, orbicularis oculi muscle, frontalis muscle

\section{Introduction}

Apraxia of eyelid opening (AEO) is a syndrome that manifests as the inability to open the eyes at will. Patients usually try to open their eyes with their hands or by contracting the frontalis muscles in the absence of any significant evidence of orbicularis oculi contraction, such as lowering of the brow beneath the orbital rim (Charcot sign). ${ }^{1,2}$ This syndrome is often found in patients with progressive supranuclear palsy, Parkinson's disease, atypical parkinsonism, and blepharospasm, ${ }^{2,3}$ but is rarely seen as the initial presentation of an acute cerebrovascular event. ${ }^{4-8}$ Herein, we report the case of a patient with AEO in which the AEO was an initial clinical symptom of right putamen hemorrhage.

\section{Case presentation}

A 91-year-old right-handed woman with a history of hypertension was admitted to the medical ward due to pneumonia. She was independent in daily life and without a documented neurological deficit.

One day following admission, a sudden onset of chest discomfort was noted and non-ST elevated myocardial infarction was diagnosed. She was transferred to the intensive care unit, where clopidogrel and aspirin were used continually, followed by heparinization for 3 days. After 7 days of this dual antiplatelet therapy, she was found to have an acute onset of difficulty in opening her eyes. A nasogastric (NG) tube was put in place to avoid choking and because she could not walk steadily. A neurologist was consulted for the eye-opening problem.
Correspondence: Yang-Pei Chang Department of Neurology, Kaohsiung Medical University Hospital, 100 Zihyou Ist Rd, Sanmin District, Kaohsiung City 807, Taiwan

Tel +886 73 I 2 II I I ext 585 I

Fax +88673162158

Email cyp905@gmail.com 


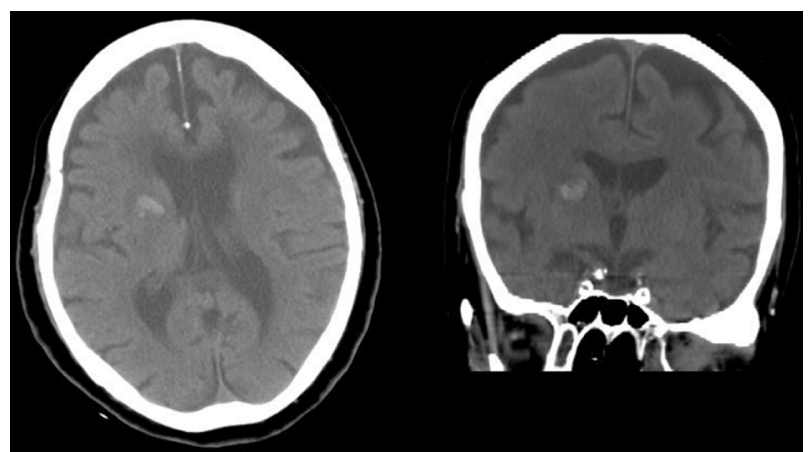

Figure I Brain computed tomography scans showing acute hemorrhage at the right putamen.

The neurological exam revealed she had difficulty in bilateral eyelid opening, left central facial palsy, mild dysarthria, and left-side hemiparesis. Pursuit and saccadic eye movements were intact. Her eye opening was especially difficult after closing her eyes tight, but she could open her eyelid after a light touch to her forehead. No ptosis or blepharospasm was noted. Brain computed tomography scans revealed an acute hemorrhage at the right putamen (Figure 1) and surface electromyography revealed persistent contraction of the frontalis muscle and relaxation of the orbicularis oculi muscles on trying to open the eyes (Figure 2). AEO was suspected.

Her eyelid opening and dysphagia had not improved 2 weeks after the hemorrhage. Half a Sinemet ${ }^{\mathbb{}}$ (carbidopalevodopa, 25/100 mg) tablet (Merck \& Co., Inc, Whitehouse Station, NJ, USA) was given twice daily for 6 weeks. Her NG tube was removed 1 month later. Her eyelid problem had subsided after 2 months of hemorrhage being identified, while brain computed tomography scans revealed that the hemorrhage had resolved.

\section{Discussion}

The case described here had AEO as the initial presentation of right putamen hemorrhage without other extrapyramidal symptoms suggestive of Parkinson's disease, progressive supranuclear palsy, or cortico-basal degeneration. As it is well known that a unilateral basal ganglia lesion can cause bilateral AEO, here we discuss the possible mechanism of this symptom in our patient.

Voluntary eye opening is controlled by the corticobulbar tract from the primary motor cortex (M1) and motor-related cortical areas, including the supplementary motor area (SMA) or premotor cortex. The basal ganglia may play a
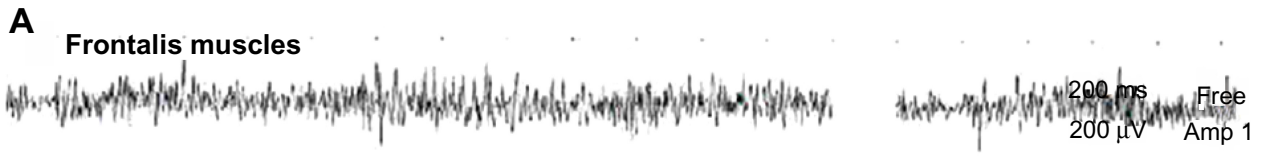

Off
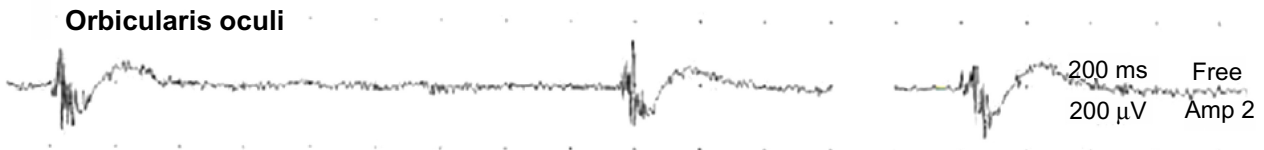

Right eyelid

B

Frontalis muscles

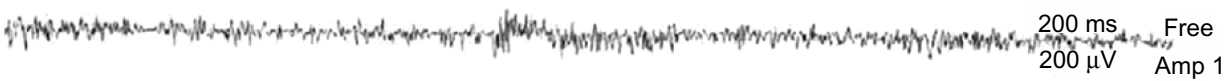

Off

Orbicularis oculi

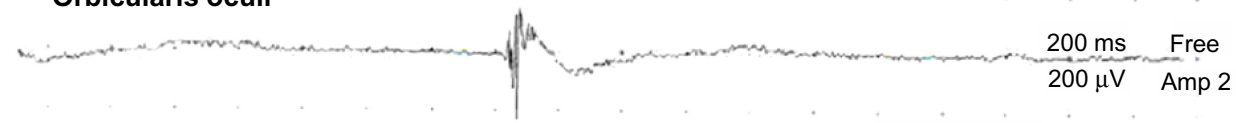

Left eyelid

Off

Figure 2 Surface electromyography was recorded at the bilateral eyelids: (A) right frontalis and orbicularis oculi muscles; (B) left frontalis and orbicularis oculi muscles. Persistent contraction of the frontalis muscle was observed, while there was rare contraction of the orbicularis oculi muscle when the patient tried to open her eyes. 
role in the regulation of the eye-opening system in the SMA through the thalamus. ${ }^{9}$ In terms of basal ganglia dysfunction, regulation may be impaired in Parkinson's disease or other diseases with parkinsonian features and AEO. On the basis of pharmacological evidence, the role of basal ganglia dysfunction in AEO has been further clarified, ${ }^{10}$ even in Parkinson's disease patients receiving deep brain stimulation at the bilateral subthalamic nucleus. ${ }^{11}$ Thus, the AEO in our patient may support the theory of a basal ganglia abnormality producing AEO.

In our case, we suggest that the right hemispheric lesion may have caused the AEO. A few reports have suggested that a right cerebral hemispheric lesion would be more likely to cause AEO because the right cerebral hemisphere controls the bilateral levator palpebrae superioris. ${ }^{5-8}$ In contrast, other reports have shown that a dominant hemisphere lesion caused AEO ${ }^{4,7}$ As for the laterality of AEO, more evidence is still required to reach a conclusion about this.

Dual antiplatelet therapy of aspirin and clopidogrel has been proven to be associated with significantly reduced major atherothrombotic events and an increased risk of moderate and severe bleeding. ${ }^{12}$ Indeed, gastrointestinal bleeding and intracranial hemorrhage are two of the most common bleeds associated with dual antiplatelet therapy. Since AEO is an uncommon initial presentation of intracranial hemorrhage, special caution should be taken and further brain imaging performed during dual antiplatelet treatment for atherothrombotic events.

\section{Conclusion}

Our patient experienced eyelid-opening apraxia secondary to an isolated right putamen hemorrhage, which is suggestive of the essential role of the basal ganglia in eyelid opening.

\section{Disclosure}

The authors declare no conflicts of interest in this work.

\section{References}

1. Zadikoff C, Lang AE. Apraxia in movement disorders. Brain. 2005; 128(Pt 7):1480-1497.

2. Miller NR, Newman NJ, editors. The Essentials: Walsh and Hoyt's Clinical Neuro-Ophthalmology. 5th ed. Baltimore, MD: Williams \& Wilkins; 1999

3. Hallett M, Evinger C, Jankovic J, Stacy M; BEBRF International Workshop. Update on blepharospasm: report from the BEBRF International Workshop. Neurology. 2008;71(16):1275-1282.

4. Kaiboriboon K, Oliveira GR, Leira EC. Apraxia of eyelid opening secondary to a dominant hemispheric infarction. J Neurol. 2002;249(3): $341-342$.

5. Algoed L, Janssens J, Vanhooren G. Apraxia of eyelid opening secondary to right frontal infarction. Acta Neurol Belg. 1992;92(4):228-233.

6. Johnston JC, Rosenbaum DM, Picone CM, Grotta JC. Apraxia of eyelid opening secondary to right hemisphere infarction. Ann Neurol. 1989;25(6):622-624.

7. Hirose M, Mochizuki H, Honma M, Kobayashi T, Nishizawa M, Ugawa Y. Apraxia of lid opening due to a small lesion in basal ganglia: two case reports. J Neurol Neurosurg Psychiatry. 2010;81(12): $1406-1407$

8. Lee SS, Lee HS. Can subcortical infarction cause apraxia of eyelid opening? J Clin Neurosci. 2011;18(10):1399-1400.

9. Costa J, Valls-Solé J, Valldeoriola F, Rumià J, Tolosa E. Motor responses of muscles supplied by cranial nerves to subthalamic nucleus deep brain stimuli. Brain. 2007;130(Pt 1):245-255.

10. Lee KC, Finley R, Miller B. Apraxia of lid opening: dose-dependent response to carbidopa-levodopa. Pharmacotherapy. 2004;24(3): 401-403.

11. Umemura A, Toyoda T, Yamamoto K, Oka Y, Ishii F, Yamada K. Apraxia of eyelid opening after subthalamic deep brain stimulation may be caused by reduction of levodopa. Parkinsonism Relat Disord. 2008;14(8):655-657.

12. Bhatt DL, Fox KA, Hacke W, et al; CHARISMA Investigators. Clopidogrel and aspirin versus aspirin alone for the prevention of atherothrombotic events. $N$ Engl J Med. 2006;354(16):1706-1717.
Neuropsychiatric Disease and Treatment

\section{Publish your work in this journal}

Neuropsychiatric Disease and Treatment is an international, peerreviewed journal of clinical therapeutics and pharmacology focusing on concise rapid reporting of clinical or pre-clinical studies on a range of neuropsychiatric and neurological disorders. This journal is indexed on PubMed Central, the 'PsycINFO' database and CAS

\section{Dovepress}

The manuscript management system is completely online and includes a very quick and fair peer-review system, which is all easy to use. Visit http://www.dovepress.com/testimonials.php to read real quotes from published authors. 